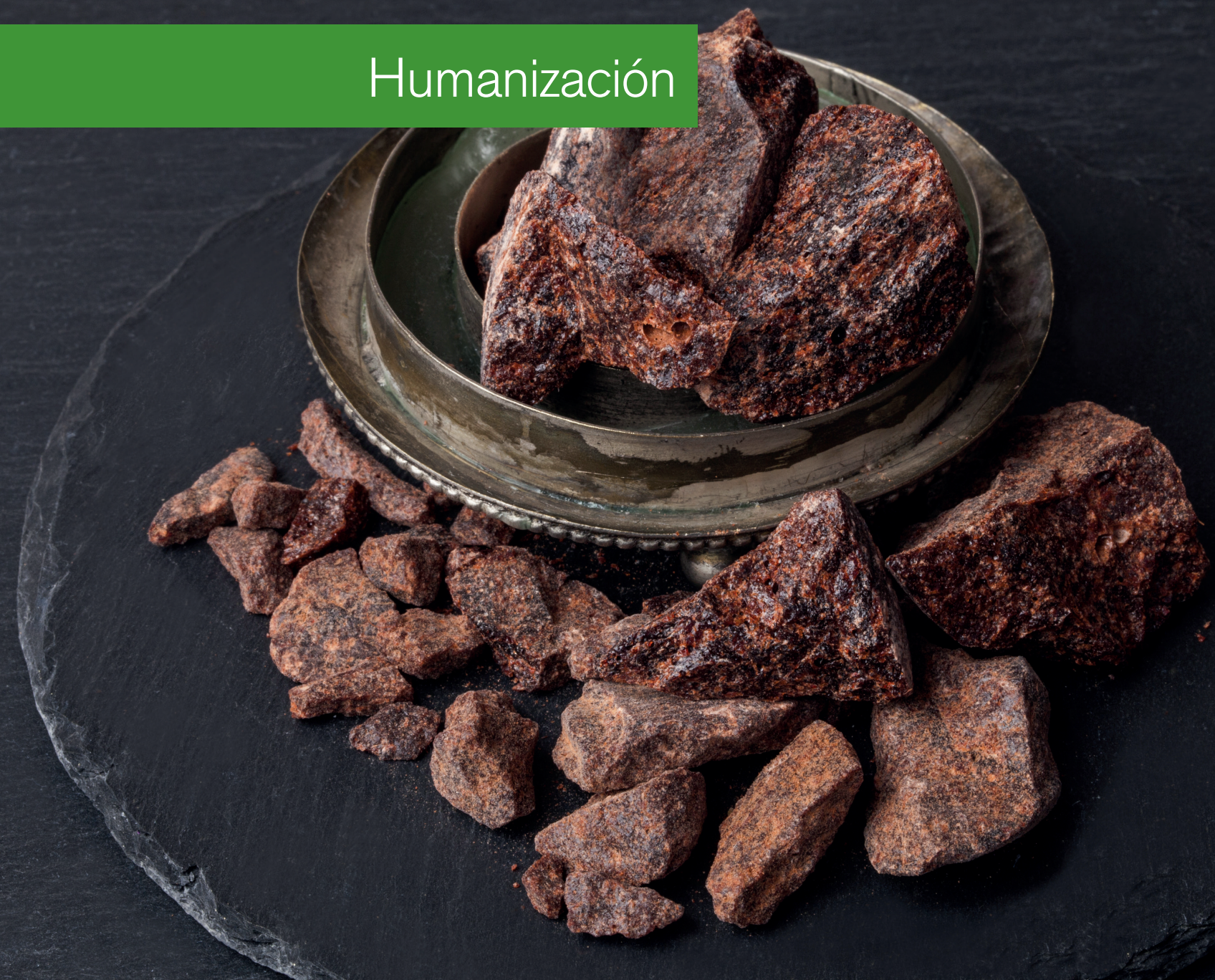

\title{
Humanization of Medicine. Historical Development
}

La humanización de la medicina. Evolución histórica

(2) Autor

\section{Salvino Leone}

Orden Hospitalaria de San Juan de Dios. Italia

E-mail: salvino.leone@tiscali.it 
Abstract

Resumen

Key words

Humanización; cuidado de enfermos; buen samaritano; historia de la ética médica; modelos de asistencia sanitaria.

En términos negativos, podría decirse que la cuestión de la humanización de la asistencia médica proviene de la deshumanización de determinadas prácticas sanitarias; en términos positivos, podemos remontarnos a las raíces ancestrales de la humanidad que ha representado la medicina. No obstante, incluso con un interés renovado, no siempre ha sido posible humanizar o rehumanizar adecuadamente las acciones del personal sanitario. A lo largo de los años han existido diferentes modelos de asistencia sanitaria (que se detallan brevemente en este artículo) y diversas fuentes de presión, tanto religiosas (como las reformas sanitarias de los santos) como seculares, para humanizar la sanidad. En la actualidad, la necesidad de renovar este proceso queda aún más patente y la "humanización de la asistencia sanitaria" debe considerarse una prioridad de la medicina actual.

Humanization; care of the sick; Good Samaritan; history of medical ethics; health care patterns.

(1)

Recibido: 18/04/2018. Aceptado: 18/08/2018 


\section{From the ancient humanitas of medicine up to the present dis-humanization}

If, since some time, we are talking about the "humanization" of health care, that's why it appears in various ways "dis-humanized". However, the very world of medicine has been characterized by an ancient and natural humanitas that, for several reasons, has been weakened so now it needs a deep re-foundation and re-updating. In this sense we can say that there have been four different paradigms or patterns of interpretation and practice of medicine.

\subsection{Magical/priestly pattern}

We can see it essentially in ancient medicine, which was exercised either in the archaic societies or in the eastern great civilisations.

- Archaic societies. There are two elements that characterize disease and medicine in most archaic societies: the disease-sacrum link and the link between illness and suffering. The first is quite understandable if we take into account the category of "sacred" in which the mysterious and incomprehensible pheno-

The world of medicine has been characterized by an ancient and natural humanitas that, for several reasons, has been weakened so now it needs a deep re-foundation and reupdating mena are ordinarily bounded, especially if they were linked to evil powers such as illness. The second one relates to the original understanding of human life as a "whole". It's a clear, immediate, bright intuition, almost lost in western culture and today laboriously undergoing to recover. The disease "ill" the man, it is not a part of him; the patient "is" bad, it is not his head or his hand to hurt as if they were outside of himself. It's in this very cultural context that the work of the doctor arises. It is humanitarian already in its own principles as directed towards the sick man. Basically there are three expressions of the "humanism" of medicine in primitive societies ${ }^{1}$ :

- Personal example. As Levi-Strauss states "the effectiveness of magic involves a belief in magic" and in turn, this is an attitude consistent with that relationship with the supernatural: so goodness, exemplary life, almost a certain natural "perfection" (Levi Strauss, 1963).

- Charisma and gratuity. In the sacral context of primitive medicine the physician/ healer is not such by a scientific knowledge but for a supernatural gift that cannot be an object of payment. Medical art is not just any other sailable profession but the exercise of a supernatural beneficial power transmitted to the healer.

- Authenticity. However if it is not a school to train a doctor, a guarantee or an authentication of his charisma is needed. This consists in a call attested by the

1 Amundsen, D. W. (1978). History of Medical Ethics: Ancient Near East. New York: Free Press; Esraghi, R. (1978). History of Medical Ethics: Persia. In W. T. Reich (Ed.), Encyclopaedia of Bioethics (pp. 880-883). New York: The Free Press. 
healer himself, either in a consecration by an elderly healer or in a prodigious event accompanying his birth, etc.

- Ancient Orient. A new historical and cultural understanding of the disease begins slowly to make its way. In small steps the disease is "expropriated" to the supernatural kingdom and re-conducted to the sphere of a natural causality. This desacralization of medicine not only doesn't affect the humanitarian nature of the medical act, rather straightens it because the sacral action is confined to a certain sphere of neutrality.

For instance in Babylon the magician-priest (asipu) doesn't hesitate to leave the des-

A new historical and cultural

understanding of the disease

begins slowly to make its way.

In small steps the disease

is "expropriated" to the

supernatural kingdom and re-

conducted to the sphere of a

natural causality perate cases while the healer-doctor (asu) takes care of the sick until the end (Esraghi, 1978, p. 883).

In Egypt, then, even the term that designates the doctor is related to the humanitarian dimension of his work. Sounou, in fact (= doctor) is the phonetic expression of an arrow (soun) on a vase (nou) followed by the determinant of the seated man. It is a phonetic and not ideographic writing that can be leaded back to the verb soun which means "to be sick, to suffer". Sounou, then, means "who of those who are sick, who of those who suffer" (Leca, 1983, p. 104). It's a really beautiful term to define the doctor.

Quite singular is the role of the doctor in ancient Persia. In fact, medicine occupies a central place in the Persian religion. In the rigid dichotomy of Zoroastrianism the doctor aligns himself on the side of Good against the forces of Evil. His humanitarian prerogatives are clearly illustrated in this text of the sixth century AD which probably follows a lost section of the Avesta, the sacred book of Zoroastrianism. The perfect doctor:

[...] must know the parts of the body, their articulation, the remedies for diseases; he must be lovable, without jealousy, kind in words, devoid of pride; an enemy of the disease but a friend of the sick; modest, alien from blame, from evil, from violence, solicitous; noble in actions, endowed with a good reputation, not working for gain but for spiritual reward; ready to listen, authoritative and philanthropist. (Esraghi, 1978)

\subsection{Empirical/paternalist pattern}

We find this model in ancient Greece, initially expressed by Hippocratic medicine and subsequently spread to the whole practice of western medicine at least until the Enlightenment.

At the basis of all the medicine of ancient Greece. This is the conception that joins medical act (philanthropia that is love for man) and philotechnia (love for [medical] art). It's well known the famous sentence drawn from Praecepta: "where there is love for man, there is also love for art". This justifies the weaving of purely technical problems with ethical problems that we find in the Hippocratic Oath: 
I will use treatment to help the sick according to my ability and judgment, but never with a view to injury and wrong-doing. Neither will I administer a poison to anybody when asked to do so, nor will I suggest such an advice. Similarly I will not give to a woman a pessary to cause abortion. But I will keep pure and holy both my life and my art. I will not use the knife, not even, verily, on sufferers from stone, but I will give place to such as be craftsmen therein.

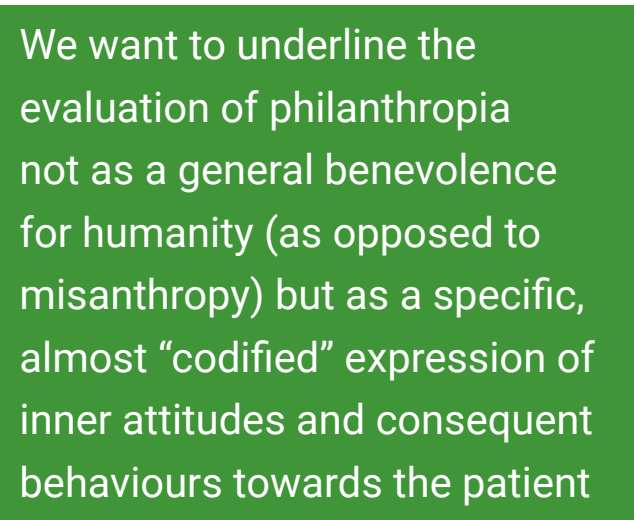

Into whatsoever houses I enter, I will enter to help the sick, and I will abstain from all intentional wrong-doing and harm, especially from abusing the bodies of man or woman, bond or free. And whatsoever I shall see or hear in the course of my profession, as well as outside my profession in my intercourse with men, if it be what should not be published abroad, I will never divulge, holding such things to be holy secrets.

We want to underline the evaluation of philanthropia not as a general benevolence for humanity (as opposed to misanthropy) but as a specific, almost "codified" expression of inner attitudes and consequent behaviours towards the patient. Four points can be considered in order to qualify the philanthropic expression of medical art.

- Technicalization of help feeling (Lain Entralgo, 1969, pp. 45-62). In Hippocratic ethics, the feeling of other's help -the philanthropic instinct shows a sort of formalization, becoming a cultural heritage of the doctor, an interior attitude, a relational attitude-.

- Relativization of medical fees. Far from appearing as an accessory element, this aspect of the Hippocratic teaching assumes many and interesting expressions. First of all, the concept of proportionality of the fee which takes into account the economic conditions of the patient and then the gratuitousness of the service where objective situations (including poverty or being foreigners) require it.

- Medical paternalism. In Greek thought there is a perfect correspondence or better a true identity between moral and natural order (that is ethos and physis). The moral order, in a certain sense, belongs to the physical order, to the only great order of the nature. If the disease is a natural disorder, as dis-order involves the deconstruction of the whole order of the individual, since this is an ethical/physical whole. If you lose one of them, then you will lose the other one too. If there is pathos (= physical disorder) there will no longer be ethos (= moral order). So, the sick (that is the subject who has the pathos) is a subject that has no more ethos. He is a "moral incompetent". So, it is clear that someone must take care of his choices and of his good both physical and moral. The suitable person to do so is the doctor (Gracia, 2008, pp. 30-108). This "medical paternalism" has remained practically unchanged until a few decades ago when the autonomism of modern thought has blow up the decisional autonomy of the patient.

- Ethical/deontological implications. These involvement, already seen in the "Oath", arises because of a certain "religious" respect for one's professionalism, whose last target however it's still the human person. Professional decorum, honesty, respect for life become for the Hippocratic doctor expressions of professionalism that can- 
not be separated from technical performance. His human qualities and his behavioural results are well described in one of the treatises of the "Corpus Hippocraticum":

\begin{abstract}
The doctor must have authority. He will have a good colour and floridity that befits his nature. For it is a common opinion that those whose physique doesn't enjoy a good status will not be able to treat others satisfactorily. Moreover he will have to be refined in taking care of his person. decency in clothing, pleasing aromas, with a discreet smell [. . . ]. As for ethics, it will have to make use of great moderation, proving not only reserved in speeches, but also perfectly measured in the conduct of life: this is decisive for a good reputation. His conduct will have to be honourable and irreprehensible and, moreover, he will be with everyone serious, humane, fair; since the hasty care brings contempt, even when it proves to be very useful. (Le Goff \& Sournia, 1986, p. 40)
\end{abstract}

\title{
1.3. Scientific/positivist pattern
}

It began to establish itself in the Middle Ages and reached its peak during the Enlightenment and the following scientific revolution that was established in the eighteenth century. In fact, some of its features are closely related to it.

- Desacralization of the body approach. The sphere of corporeity, at least until the Middle Ages, is surrounded by an aura of sacredness, partly of Christian origin (as the fruit of a participation to the creative power of God), partly of Platonic thought (as a "container" of the spiritual principle that is the soul). This explains the severe prohibitions imposed in 1300 by a bull of Boniface VIII against the anatomical dissection considered a real desecration. Despite such prohibitions,

The sphere of corporeity, at least until the Middle Ages,

is surrounded by an aura of

sacredness, partly of Christian

origin, partly of Platonic thought in 1316, the Bononian doctor Mondino de' Liuzzi performs probably the first systematic dissection of a cadaver: the great barrier of bodily intangibility is practically broken. Beyond the scientific interest, Mondino's work (Anathomia overo dissectione del corpo humano) inaugurates a new culture in the history of medicine: a rational, cognitive, rigorously methodological approach to human corporeity but at the same time its "objectification", reduction of the intersubjective relationship to subject-object relationship.

- Therapeutic cruelty. We use this term in its true meaning, that doesn't mean almost a sadism on the part of the doctor, but the actual "raw" reality of therapeutic resources, at least terrifying that could imply by those who used them a certain impassivity towards the suffering of others. Potions from the most repellent compounds, amputations, cauterizations, phlebotomies, hot or icy baths, constituted the ordinary therapeutic arsenal of doctors and surgeons. Of course, there wasn't any anaesthesia, and the effects of some of these practices (which today we would call "iatrogenic" damages) are really deleterious.

- Technological achievements. Another cause of dehumanization more and more decisive today is the high technological level reached by contemporary medicine. From 
the easiest occurrence of laboratory tests to nuclear magnetic resonance a complex network of instrumental aids is today interposed between the doctor and the patient. Without prejudice to some fundamental assumptions of classical semeiotics, modern diagnostics is no longer "on the sick" but "on the results" provided by the various investigations to which it has been subjected. All this creates a sort of great filter that the physician must return to the patient "decoded" in a therapeutic choice.

\subsection{Pragmatic/economic pattern}

- Nationalization of assistance. One of the most advanced achievements of a modern State is health care for its citizens. Aware of its essential function as a tutor of the public good, the State system now considers that as a priority. Regardless of the more or less effective technical solutions, of the underlying political ideologies, of the different expressions, this State duty has a risk, i.e. the bureaucratization which, if the System is in a precarious equilibrium, risks the collapse with all its dehumanizing power. Then the patient turns into a simple practice to be authorized, the doctor in a bureaucrat who counts the number of assisted people or extra hours and the hospital in a health-giving company. The sick disappears in front of the structure which, paradoxically, exists according to his health. All this is not just a bad functioning of the health service or the simple application of an inadequate legislation. However, as it is a calculated risk it is also predictable and, as such, can be carefully "monitored" and avoided.

- Neo-religious status. Today, a new sacrality is opposed to the desecration previously detected. The divine thaumaturgical power, of which the healer of a time was medium, today is an effective therapeutic possibility. And the more this possibility solves complex serious, sometimes desperate, clinical situations, the more the protagonist is confined to this aura of new sacredness; The myth of the famous surgeon

Then the patient turns into a simple practice to be authorized, the doctor in a bureaucrat who counts the number of assisted people or extra hours and the hospital in a health-giving company or of some medical "stars" came up. Here we don't want deal with the actual correspondence between "what is" and "what appears", that sometimes is a real correspondence but sometimes sometime not, but underline: either the phenomenon or its negative implications in the area of dehumanization. Looking for the skill of the doctor is not only understandable but also dutiful; it is also conceivable the gratification that the doctor can draw from his competence while it's inadmissible his "exploitation" at least on two sides: the economic and that of power one. Even in his occurrence we don't want to deny the honesty of a salary absolutely proportionate to the skills, risks and responsibilities. We only want to deny the spasmodic search for this above and beyond the person who requires therapeutic performance. Likewise, it is evident that certain roles in the society involve ipso facto the conferment of a "power" but nothing is worse than a power that one cannot manage. If power means "to have the possibility of" it will be authentic and beneficial the power used in function of the other, of human progress, of the promotion of a greater psychophysical wellbeing, of the 
improvement of the health structure, of research; in a word: power-for-the-other and not power-for-itself.

- Enforcement of the economic-financial model. Dealing with this aspect, a preliminary consideration is constituted by an apparent contradiction: health is priceless but costly. It is like the "central dogma" of health economics, from which we can clearly understand how any solution to the problems has a sort of constitutive inadequacy, given that it is part of an unresolved conflict between the "infinite value" of health as a good and the limited resources to guarantee it. Today, this dialectic is accentuated even more as the two terms of the relationship progress in inverse proportion. That is either the increased cost due to an increased need for health, or the decreasing of available resources decrease for the increased "cost" of some diagnostic procedures (CT, PET, bone densitometry, etc.) and therapeutic procedures (interferon, epoietine, anticancer drugs, immune therapy, etc.) and for the reduction of public funds allocated to health.

- Loss the person centrality. It is certainly the most important element of contemporary "dehumanization" and the one were the others converge. Obviously, all this has

After all we can say that

everything defending, protecting,

promoting the person was "good" slowly established itself in contemporary culture and above all by what has generally been called "weak thought". That is a thought that doesn't know how to elaborate concepts and "strong" contents, value points of reference to look and to realize. First of all, in fact, the person. The whole philosophical, ethical and juridical reality of the previous centuries had centred on this entity. The person was the holder of every human right, he was the last instance (at least in human terms) to which one must refer. And at the same time also the basic criterion of moral judgment on human actions. After all we can say that everything defending, protecting, promoting the person was "good". Today isn't more so. There is even a debate about the existence itself of the concept of person.

\section{The humanizing pulls}

In the historical evolution of medicine, it is possible to identify two fundamental moments that have concentrated the best of the "humanizating" trends in the course of history. These tendencies are the result either of a reaction to historical moments of particular dehumanization, or of a "filiation" of specific cultural sources from which they originated.

The first of them grew in the area of Catholicism; the second one is almost contemporary and expresses itself in different, secular patterns.

\subsection{Christian assistance to the sick}

- The culture of health in the first five centuries of Christianity. In the history of Christianity and therefore of the Church, the assistance to the sick plays a special role. 
First of all for the place occupied by it in the life of Christ whose healing miracles constituted a large part of his life, secondly for the specific command given to his disciples: curate infirmos (Lk 10,9). Resulting from this command, the rising Church organizes the first forms of assistance to the sick. The first health care institutions were, probably, the diakonias established in Rome by Pope St. Fabian (240-253) and joined to the offices of the Bishop in order to take care of different categories of people in need. At the Council of Nicea (325) the xenodochia, great "hospices" for foreigners, pilgrims and sick people began to be mandatory for each city. In 331 St. Basil built the famous Basiliade, the first "hospital facility" of ancient time. The Benedictine reform marks a turning point also in the assistance field. The attention to the sick person is no longer expressed in a generic hospitality or in an invitation to resignation but in an effective work for the psychophysical well-being of the patient.

Thus "infirmaries" are born in the monasteries. The Benedictine

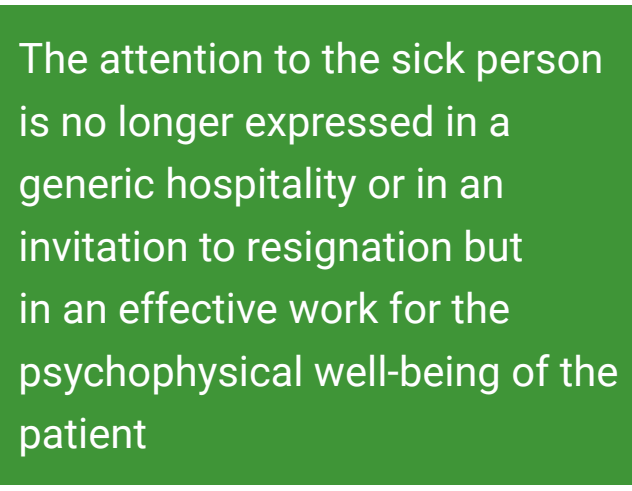

Rule reads:

The care of the sick is first of all and above all, so that no negligence is used with them. A particular cell is assigned to the sick brothers, as well as a God-fearing, diligent and solicitous servant. Both the use of the bath is prepared whenever the opportunity arises.

Besides the Benedictine monks begins to devote him to the study of medicine and herbal medicine. This is a tradition that continues until today. Together with its application, medical science is researched, investigated and studied as such. In a sense, the Benedictine monk as well as a doctor is also a "researcher". In the Middle Age, then, the humanitarian ideals of the Chivalry became concrete in the institution of military hospital of chivalrous orders. Among these we remember: the Gerosolimitan Hospitaller Order called the "Giovanniti"; the Hospitaller Order of S. Lazar (whose knights were obliged to live forever in the Hospital); the Teutonic Knights Order (which also served of «ambulance» during papal voyages).

- The "reformist" saints of health care. In order to well understand the environmental impulses (whose role fully belongs to the vocational dynamic) it is necessary to give a synthetic glance to what could be called the "failure" of the Renaissance in the assistance field:

A crowd of disturbing and incurable people, affected by the new disease that had been imported from the West Indies, the syphilis, were covered with filthy sores, which were severe; they were incurable by the therapeutic means then available, rejected by every hospital and by their own homes. They were roamed in the squares and streets, where they died abandoned by everyone. Convalescents of serious illnesses discharged from the hospitals often exceedingly full, sometimes also died in the streets, because there wasn't any hospice in which they could acquire the forces to overcome a life of hardship and deprivation. Individuals deprived of the use 
of reason, put to the chariot of the mob, once mocked and beaten, without a bed to rest, also wandered from town to town, from square to square. But this condition was better than the one waiting for them when they became dangerous for maniac accesses, when they were hospitalized in filthy prisons where the treatment was not for the good of the sick but for the confession of the most nefarious crimes. (Pazzini, 1958, p. 146).

Probably above all there was that idealizing aesthetic of the Renaissance that enhances the beauty, the culture, and the artistic gifts in the man and, in the structure, the harmony, the perfection, the composure. The patient is the nega-

The patient is the negation of all this and the cultural matrixes of the classics certainly do not help to enhance it tion of all this and the cultural matrixes of the classics certainly do not help to enhance it. Even the hospital is more at the service of art than of the sick: just think of the Hospital of the Innocenti in Florence with the famous medallions by Luca della Robbia, at the Ca 'Grande in Milan, at the Hospital of Saint Spirit in Sassia of Rome. Chronic patients suffering from repulsive diseases or those unable to walk could not access the "general" hospital, thus being relegated to the hospitals of the "Incurables", or even to the hospitals usually prepared by the Church to face these marginalizations. In this socio-cultural substratum the work of St. Camillus De Lellis, St. John of God, St. Vincent de Paul arise. Different in terms of nationality, temperament, life experiences, they are united by the great project of reform towards assistance to the sick.

- S. Camillo de Lellis (Bucchianico [Chieti] 1550 - Rome 1614) converted at the age of 25 years after an adventurous life he got to know the hospital degrade as he was hospitalized for a recurring leg plague. From being a patient he becomes "nurse", becoming part of the staff and receiving tasks of ever greater responsibilities up to cover the apical role of who we could now call "managing director". Having thus, known closely the hospital reality and identified among the hospital staff, five particularly helpful persons organized with them the first nucleus of what will be the future congregation of the "Ministers of the Sick" (better known as "Camillians"). S. Camillo in his Regulae has repeatedly outlined the ideal figure of the health worker: diligent, vigilant, competent, ready, attentive.

- St. John of God (Montemor-o-Novo [Portugal] 1492 - Granada 1550 ) He was an adventurous and, in many ways, even mysterious, man whose life was marked by a continuous research of fully gratifying experiences, by a continuous existential stress towards something that only around forty years will succeed, in a dramatic way, he will find. In fact, the human vicissitudes of the saint undergoes a breakthrough, exploding into a sudden conversion for which it was considered mad and restrict in the mad area of the Granada Royal Hospital where he was treated by the usual repressive methods of the time, That's why he decided to dedicate his life to the sick by asking God to be able to cure them "in his own way." In order to do this, he gathered a small group of willing people turning around Spain and exhorting "do good brothers", a motto with which it is now known, in some countries, his Order. The hospitals of St. John of God gave a decisive turning point to assistance by anticipating the modern 
welfare criteria: subdivision of the hospital into departments, isolation of the contagious sick, single bed for each patient, occupational therapy, psychotherapy, etc.

- St. Vincent de Paul (Pouy [Francia] 1581 - Parigi 1660). Also he must be associated with these two great reformers. In fact, even if his work was not destined to give priority to the sick, his great care project towards the "poor" of every kind includes even the sick. Moreover, he is credited with having set up the first "School for professional nurses" and a community of nuns released from the cloistered life and dedicated to home care, hospital, etc. No longer with the typical flapping hats, as was the habit of the past, they are still widespread and operating all over the world.

\section{From past to the present}

- The secular contribution to humanization. Alongside these movements that have sprung up about half a millennium ago and are still present in the world, we must support a series of cultural currents dating back to the last cen-

In the health field all this turns into a particular attention for the psycho-physical-social wellbeing of the individual tury, which have emphasized the humanisation of medicine in various ways. The ideological and cultural aspects of this century can be divided into four main orientations in this sense. This is not a complete list of "movements", always well defined but undoubtedly the incidence that these attitudes have had on the issues related to humanization must be considered particularly significant.

- The first matrix must be identified in the culture of the body re-appropriation that comes from a reaction to the tabuization of the past and to the "body expropriation" performed by the technology. In the health field all this turns into a particular attention for the psycho-physical-social well-being of the individual. It doesn't consider more the simple "disease" from which one must be healed but the global "sick humanity" of man that must be healed

- The second aspect is constituted by the ideological-cultural wave that gave rise to different organizations for the rights of the patient. Even if, sometimes, they encourage a real conflict against the doctor in the meanwhile they are meritorious in the defence of all the rights of the sick.

- The reactive attitude towards the current deterioration of health care is related in a sense with the previous one, and has been strongly stigmatized by Ivan Illich who, in his famous "Medical Nemesis" stresses how the medicine itself and its social spreading could be the first cause of illness. So, if you want heal the sick you must "heal the medicine" and the society.

- Finally, another important contribution comes from the greater social sensitivity of contemporary people towards the categories of exclusion: the elderly, psychopaths, drug addicts, disabled people, ex-prisoners, and sick people. Even if in the world still persist attitudes of exclusion or out-end-out hate generally laws and thought consider all these people as vulnerable subjects that need our special care. 
- The humanization of nursing. It's well known that Florence Nightingale, at the beginning of the 19th Century "founded" the true nursing assistance constituting the principles of modern nursing. For it the sick person is not only an ill body to be treated but a person to be assisted in full. The mixture between cure and care is very clear in its work, which then became the basis not only of the nursing assistance but of the most global humanized assistance to the sick person. In his wake is Virginia Henderson (Kansas City 1897 - Branford 1996) who publishes Principle of Nursing

At the base of the

dehumanization beyond all the

different historical variables,

there is the absence of putting

the sick at the centred of health

care translated into more than twenty languages in which she links all nursing assistance to the total needs of the person. She defines nursing with this touching words:

The nurse is temporarily the consciousness of the unconscious, the love of life for the suicidal, the leg of the amputee, the eyes of the newly blind, a means of locomotion for the infant, the knowledge and confidence of the young mother, and a voice for those too weak to speak. (Enderson, 1964, p. 63)

- The "relaunch" of the theme. In the " 80 s the theme of humanization was "re-launched" by the General Superior of the Hospitaller Order of St John of God, brother Pierluigi Marchesi (1981) in a document initially directed to his Order but then spread in the entire health world. In them there was not only a thematic discussion about humanization, but it was seen as an unavoidable necessity since the dehumanization in progress of the health world. Starting from a privileged position of "observer of the world" given by his role as General Superior as well as being the chief of an Order dedicated to a wide range of health care broche, bro. Marchesi had the opportunity to see that the world health reality was everywhere and in a different way dehumanized. His writings also had the merit of re-emerging the term "humanization" which, since then, has spread and has come to the attention of all those who believe in a humanized change in the health care. Among the fundamental points of his thought we can highlight the following ones:

- Man as a centre. At the base of the dehumanization beyond all the different historical variables there is the absence of putting the sick at the centred of health care. Superstructures, bureaucracy, personal interest, working dynamics have in some way marginalized the sick. What is done is not always done for him, but he takes into account other factors that are flattering from his effective needs.

- The importance of not going "beyond" man. Sometimes it almost seems that man is bypassed. Often, we talk about health areas of trade, careerist, academic nature for which man seems almost an instrument or a pretext to do something else. In any case, the total dedication of a time is often reduced to a simple job in which the patient, more than the object of professional passion, is an annoying interlocutor to be liquidated as soon as possible. All this, however, extends, and in some areas, runs out in the relationship with his family often seen as a troublesome obstacle to his work more than people involved in the experience of illness of his relative. 
One cannot humanize if he/she is not humanized in turn

To humanize oneself in order to humanize others. Many times, when we talk about humanization, even with the best intentions, we aim at the relationship between the health worker and the patient and the need to humanize it in the best possible way. Almost always it's neglected a fundamental aspect concerning the welfare state of the health care worker. In fact, one cannot humanize if he/she is not humanized in turn. As an ancient Latin maxim used to say: nemo dat quod non habet (nobody gives what he hasn't have). For example, in the humanized approach to the sick, it is necessary to evaluate, for example, not only its environmental comfort but also that of the staff who assists him, his work rhythms, the relationship between peers and superiors, the right gratification not only economic but also human, the promotion of his professionalism, etc.

- A "Samaritan" humanization. Finally, as a synthesis of what we have up to now, the words of John Paul II: "Good Samaritan is every man who stands next to the suffering of another man $(S D 7,28)$ legitimize a" lay "reading of the known parable seeing in it the stages, or better, the different aspects of the humanization of medicine. Referring to the different moments of the parable we can thus be updated with reference to the topic we are dealing with:

- He saw him. The first step is to "become aware of the sick person". Obviously, it is not a matter of his physical presence but of all his needs, especially those that are not expressed. In a certain sense it is necessary to "listen to what he doesn't say".

- He had compassion. The Greek verb is splagchnizō which recalls the splagchnos i.e. the viscera. To have compassion means to participate "viscerally" in the need of the other.

- He bent over him. To humanize means to abandon one's own positions, one's cultural, intellectual, and social supremacy to put oneself at the level of the other and to understand his universe.

- He bandaged his wounds. That is, he immediately prepared the best he could to remedy the situation. He did not invoke the absence of the structures, of the staff or of the others, but he re-arms and does his best. All the rest will come later.

- He poured oil and wine. That is, he resorts to his creativity by preparing what he had available to alleviate the pain and disinfect the wounds. Humanizing means often having creativity in favour of the sick person.

- He loaded it on his horse. We could say in a simple paraphrase "he took charge of it" by sharing with him the main resource he had for his journey, that is the horse.

- He took him to the inn. That is, we endeavour to give him a more appropriate arrangement by involving others; today we could say "the society".

- He took care of him. It's a term of extraordinary density expressed today in the concept of care for which the Samaritan takes globally care of the sick.

- He paid for him. That is, he puts his own. Not only that, but in doing so gives a great witness of how the other, the patient, should be helped by using their own resources. 
We know well how the parable ends. In the evangelical context it has a strong Christological and parenetic value related to the theme of charity. But, as we said before, it can also be subject to a lay reading. The invitation to do the same, then, could be well considered in terms of a renewed commitment to the humanization of care.

\section{Bibliography}

Enderson, V. (1964). The nature of nursing. American Journal of Nursing, 64(8), 62-68. DOI: https://doi. org/10.2307/3419278

Esraghi, R. (1978). History of Medical Ethics: Persia. In W. T. Reich (Ed.), Encyclopaedia of Bioethics (pp. 880883). New York: The Free Press.

Gracia, D. (2008). Fundamentos de Bioética. Madrid: Editorial Triacastela.

Lain Entralgo, P. (1969). El médico y el enfermo. Madrid: Guadarrama.

Le Goff J., \& Sournia, J. C. (1986). Les maladies on tune histoire. Paris: L'Histoire/Seuil.

Leca, P. (1983). La medicine egyptienne au temps des pharaons. Paris: Dacosta.

Levi Strauss, C. (1963). Structural Anthropology. New York: Basic Books.

Marchesi P. L. (1981). Per umanizzare l'ospedale. Roma: Centro Stampa Fatebenefratelli.

Pazzini, A. (1958). L'ospedale nei secoli. Roma: Orizzonte Medico. 